Chirurgia (2020) 115: 537-540

No. 4, July - August

Copyright@ Celsius

http://dx.doi.org/10.21614/chirurgia.115.4.537

\section{The Medical Internship: An Impossible Resuscitation}

\author{
Mihail Mihailide
}

A colleague of mine who, like me, used to vigorously browse through the volumes borrowed from the "Bibliothèque de l'Hôtel de Ville" (of Rue de Lobau), pressed for time by the scholarship, saw me heading for the clerk to return mine, got up, rushed towards me, greeted me and said: "I have an extra ticket for tonight at the Salle Pleyel, the famous Katia Buniatshvili is playing Liszt; more of us are already going, some are doctors, maybe you would like to meet them...You must have heard of the legend of Franz Liszt being the father of our great Carol Davila and the countess d'Agout, a story that their son neither con'firmed nor denied."

I immediately accepted, the hall was on Rue du Faubourg Saint-Honoré, a mere block away from the attic where I had rented a room.

A smoking being out of the question for me at the time, I just put a bow tie over my white shirt and at the time we agreed upon I entered. The hall was full to the brim. The seats were indeed grouped, mine next to my library buddy.

Katia - in a low cut, bare-shouldered dress, and Andrey Boreyko - an ascending orchestra conductor schooled in Sankt Petersburg both walked on stage.
The young pianist, born in Georgia and barely 25 at the time proved to be a specialist in Liszt, playing the piano virtuously and the number 2 orchestra, brilliantly. A big round of applause, a bouquet of flowers, not just a sheaf of printed paper like we see nowadays, and her compliments spoken in an impeccable French. (A long time after that, in December 2018, I had the chance to hear her again at the Athenaeum...).

During the break I was introduced to the others, four of which were, indeed, doctors. We commented on the performance and exchanged cards.

I remembered this moment recently, when I was offered a book on a unique subject: the history of the internship and externship in medicine, a successful form of education, taken from the French Medical School system.

University professors Benone Du $\square$ escu, Maria and Mircea Beuran, with an interest in the history of the profession but also paying attention to the evolution of the medical teaching system, propose to readers (Romanian Academy Publishing House, June 2020), based on both archive research and personal experience the book "The internship in Medicine and Pharmacy: part of the essence of Romanian Medicine" (125p). 
On the cards we exchanged that night at the concert was invariably written, as a title of honor, above all else: "Ancien Interne des Hôpitaux de Paris." Before the abolition of medical private offices - I wasn't yet a university student at the time - doctors used to write on their signs, after their specialty, former intern of one of the great hospitals from either home or abroad.

The preface is signed by Academy member Constantin Popa, while the afterword is written by Prof. Dr. Ion I. Bruckner - also former interns of Bucharest's Medical Services, the former confirmed after an exam and "assistant étranger" at the "Salpétrière" in the seventies.

Those - like many other personalities of the national medical pantheon - bring justified homage to this education system, now history (p. 15), without being obvious to us, however, by what means, through the positions they held both in the past and today, they fought the obliteration of this "exceptional form of professional training".

This used to be, according to Academy member C. Popa, the most precious title for those who attended medical schools in France and other European countries and who, with all the knowledge they gathered this way, continued to practice with pride, back home.

In the preface, the writer cites great names of national medicine: Basil Theodorescu, N. Paulescu, Thoma Ionescu, C.I. Angelescu, Iacob Iacobovici, Gh. Marinescu, George Emil Palade, Ion Juvara, Amza Jianu, Vlad Voiculescu, and so on - an edifying yet incomplete list of the former medical interns which contributed to the development of both Romanian and universal medicine.

As such, Gh. Marinescu - the favorite student of Jean Martin Charcot, father of modern neurology - after eight years of studying at the "Salpétrière", returns to Bucharest in 1897 to create the second Neurology school in the world, after the one built by his former supervisor and teacher. "The work of Gh. Marinescu still dominates today's modern neurology" (says Academy member C. Popa).
In Romania, the medical externship and internship in hospitals dates back to 1860 , merit of Carol Davila, organizer of the Health system, fortunate "import' for our country.

Davila considered the externship and internship as leading elements in the creation of the national Health system: the formation of domestic physicians (p. 27).

In France, the internship was introduced in 1802, with Davila himself an intern at HôtelDieu d'Angers, however in Europe such medical internships are believed to have been in existance since 1732 , with admittance to the internship only by exam.

Davila, promoted to general and member of the leadership of the Hospitals, was able to influence the formation, by means of the medical externship and internship of physicians with a solid professional training.

As part of the regulations of the "National School of Medicine and Pharmacy" (1857), he envisioned that "graduates of the five years of theoretical classes are to serve the next three years in the hospitals".

This provision was first applied for the army's hospital, with students named "externs".

Professor Dr. C.I. Angelescu (1869-1948), surgeon and minister of public instructions, dignified successor of Spiru Haret, with the occasion of the $75^{\text {th }}$ anniversary of this professional training method, the medical internship, noted its benefits, while Professor Dr. I. Nanu Muscel suggested improvements: the admission test should be the only way of selecting who should obtain these "initial degrees" in the medical hierarchy; those admitted should have training stages in both internal medicine and surgery; the interns should acquire, besides the traditional clinical exploration methods, modern, up-to-date medical examination methods, with the interns, treated as a sentinel of the emergency room, should live in the hospital.

In the book "The confession of a winner", published, I believe, in San Diego, by the medical historian Radu Iftimovici, George Emil Palade relates what the years of internship in the hospitals of Bucharest meant to 
him, while being an assistant to Professor Rainer, with nights spent at the emergency room where he saw the most diverse cases: a most valuable, unforgettable experience.

The authors recognize the following stages in the evolution of the medical internship: 1860-1919 - the classical internship, structured after the French model; 1919-1945 - the phase of the well-established, organized internship and the establishment of the Association of the Hospitals' Interns; 19451978 - the phase of diversification, in hope of increasing its efficiency; 1978 - the generalization of the internship "as practical training stages, but, in fact the final year of the glorious road of this unique institution of Romanian medicine and pharmacy."

In the following chapters, the authors expand upon the objectives of the listed phases, using testimonials of former interns (C.I. Angelescu, Iacob Iacobovici, Ion Chiricuță, I. Nanu-Muscel, Thoma Ionescu and so on), by presenting documents, classifications (including the distribution by sex of the medical interns - a benefit of democracy, by allowing girls to access the medical school system); and review the foundation of the Association of the medical interns, in 1918 (with the first session on the $21^{\text {st }}$ of February 1919, held in the "Coltea" Hospital Lecture Hall), miraculously saved and found in a cloth folder, revealing the duties of the Association such as establishing a library and selecting members to fill certain positions.

One of the following chapters I found to be especially touching - "Tribute to the colleagues fallen in duty", during the Independence War, during the First World War (under King Ferdinand I and Queen Mary), the foundation of the Journal "The Hospital" and the Interns' Magazine (1938).

Also quoted here are the names of some Romanians who managed to be admitted as interns in some of the most famed French hospitals as well as the activity of similar organizations in Cluj and Iasi.

In 1971, the internship was "reorganized": 3 years, starting from the sixth year of medical school, divided into: clinical studies, surgery, pediatrics, laboratory, hygiene and epidemics, dental medicine and pharmacy (the last two lasting two years instead of the usual three). Upon completion, graduates were able to enroll in the "secondary cycle" - the current residency.

The authors also remind us of the fact that, during communism, besides the usual examinations, the rules also mentioned a new element: the political approval and the social activity test graded with 1 to 20 points that were added to the main medical professional exam score to generate the grade point average and thus the classification of the candidates. The application had to be approved by the dean's office, by the UTM secretary and by the president of the Medical Students' Association on a special form..."The history of the internship and externship starts to shake" starting in 1964 (p.100) by means of less-than-brilliant "reforms": the "concept" of generalizing the externship: training stages for senior-year students (which eliminates the admittance exam).

Heads of hospitals criticized these training stages in hospitals (the large numbers of externs and the small number of teachers, the unsystematic attendance, and the lack of mandatory on-call duty and so on).

The internship system used to select a limited number of students and lasted for two years after graduating medical school.

The number of potential specialists was thus reduced from the start. In 1978, by decree (and other ambiguous later legal additions), the internship is generalized. "So comes the end of this exemplary history of the internship...which is eradicated as an institution by its generalization and transform into mandatory practical training stages."

Due to the lack of monetary funds, the system of "honorary" internship comes into existence (1958). "Those honorary or by choice interns had all the rights and duties apart from retribution (p. 80).

Memoirs of interns about themselves and their teachers comprise most of the final chapters, some of them recollections - in cursive, others already published in other 
works (Professors: B. Dutescu, Traian Oancea, intern at the Central Military Hospital, future doctor-general, Eugen Mareş, future Minister of Health, Ion Juvara; Vlad Voiculescu, famous neurologist; the accounts of the great surgeon Dan Setlacec taken from his book "European Romanian Medicine (1918-1940)" or from the marathon interview of Dr. Dora Petrilă in the book "Memoirs, Opinions, Confessions" (2009); Maria Dorobanț - in her book "A heart for hearts" and so on.

In the afterword, Prof. Dr. Ion I. Bruckner recalls his teachers from which he learned so much during his internship. Cherished mentors include Matei Balş, M. Voiculescu, Silvia Bruckner, Fl. Căruntu, M. Angelescu (infectious diseases); L. Gherasim, Al. Ioan, Pompiliu Popescu (internal medicine "Colțea" Hospital), Dan Rădulescu, Al. Prişcu, I. Busu (surgery - „Cantacuzino” Hospital)...

Concluding, the author of the afterword rhetorically asks: "could the internship make a comeback? Probably not! In order for it to come back, the numbers of residents should decrease, meaning no more than one training physician for every ten hospital beds... Some graduates of the new Internship program should be allowed to become specialists after four years directly (without any other exam). Unfortunately, the internship disappeared even in the country where it all begun, France." 